\title{
Person-Centered Psychiatry as Dialogical Psychiatry: The Significance of the Therapeutic Stance
}

\author{
Laura Galbusera $^{a}$ Thomas Fuchs ${ }^{b}$ Rainer M. Holm-Hadullac Samuel Thoma ${ }^{a}$ \\ ${ }^{a}$ Department for Psychiatry and Psychotherapy, Immanuel Klinik Rüdersdorf, Brandenburg Medical School, Berlin,

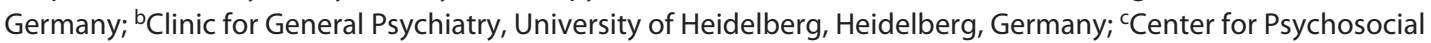 \\ Medicine, University of Heidelberg, Heidelberg, Germany
}

\section{Keywords}

Person-centered psychiatry · Therapeutic stance · Dialog · Openness · Authenticity · Schizophrenia · Psychosis .

Intersubjectivity · Personhood try must necessarily and automatically be interperson-centered and dialogical. In the concluding remarks, we finally discuss broader societal implications and outline future research perspectives.

\begin{abstract}
In this article, we present holistic and person-centered perspectives in psychiatry, with the aim of better understanding what a focus on personhood might really mean and what clinical implications it might have. We first introduce classical and philosophical concepts of personhood, in order to then outline person-centered approaches in psychiatry, which mainly focus on the person of the patient. We then argue that, for it to really be person-centered, psychiatry must necessarily also focus on the person of professionals. We thus explore the notion of stance, as the expression of the therapist's personhood. By unpacking the effects that a professional's stance can have on patients, we finally turn to a consideration of the interpersonal sphere. More specifically, we propose clinical considerations on a therapeutic stance that strives to support and to help the person of the patient unfold. Such a stance must - we argue - necessarily be a dialogical one. Drawing on these considerations, we thus claim that a truly person-centered approach in psychia-
\end{abstract}

\section{Person-Centeredness in Psychiatry}

In the last decades, person-centered approaches have increasingly developed and gained attention within psychiatry. This could be considered as a reaction to the mainstream medical model, which mainly focuses on symptoms and signs as manifestation of neurobiological dysfunctions. In contrast to this objectifying and reductionist view, person-centered approaches call for a full consideration of the person of the patient in her entirety. In this article, we first present person-centered alternatives in psychiatry and then aim at critically considering what putting personhood at the center of psychiatry might really mean. In the last section of the article, we will more specifically refer to schizophrenia and its treatment since it is one of the most paradigmatic disorders for psychiatry [1].
Correspondence to:

Laura Galbusera, 8laura.galbusera@gmail.com 
Person-centered approaches mainly draw on classical and philosophical concepts of personhood, rooted in ancient Greek and Latin culture, where the term persona indicated the mask actors wore in plays. Based on this etymology, personhood has been defined as being related to the social status or role an individual is given in society $[2,3]$. Additionally, in the Western tradition, personhood is rooted in Christianity. Instead of designating a social role, the concept of person here refers to one's intimate relation to and involvement with God. Later, in the course of enlightenment, a person has been increasingly conceived of as the self-referring, stance-taking subject capable of making autonomous, nonsubstitutable decisions.

These 2 definitions of persona are not mutually exclusive, but they tackle 2 important complementary and defining aspects: social relatedness (and thus dimensions of sociality/participation) and self-relatedness (and thus dimensions of individuality/distinction). Especially in the philosophical anthropology of Helmuth Plessner [4] one can find a synthesis of these 2 dimensions: according to Plessner's concept of "eccentric positionality" - which for him is a defining feature of personhood - we are positioned both within and without our own being and are hence capable at the same time of experiencing the world from a first-person perspective and of taking the point of view of others (i.e., the third-person perspective) toward ourselves. Personhood consequently is a category that unifies the dichotomy of individuality and sociality by mediating our individual being with social norms and expectations and vice versa. It is the dynamic gestalt and process unfolding between the 2 (see also [3]).

Importantly, this dynamic process introduces a peculiar fragility into human existence: we sometimes might lose our balance between social participation and distinction from others which may under very critical circumstances result in experiences of extreme isolation or on the other hand of merging with others, as perceived in schizophrenia [5-7]. Such imbalance might threaten the very sense of being a person and - as we later suggest might consequently be of crucial importance for a psychiatric treatment approach focusing on personhood.

Over the last century, philosophical theories emphasizing the subjective and person-centered perspective have inspired different approaches to psychiatry. A first notable example is phenomenological psychiatry $[3,8]$, which has put an in-depth exploration of patients' firstperson (i.e., subjective) experience at the heart of psychiatric theory and practice. Moreover, specific social-psychiatric (e.g., $[9,10])$ and psychotherapeutic approaches (e.g., [11]) have aimed at centering treatment on the needs, unique characteristics, and sense-making of the person.

Currently, such perspectives constitute the basis for and have been integrated within the newly established person-centered approach in psychiatry, which has been developed since 2005 by Mezzich et al. [12]. The aim of current person-centered psychiatry is to promote the health and well-being of the totality of the person, implying the recognition of the individual subjectivity beyond what characterizes a mental disorder or the status of patients. The focus is thus not exclusively on symptoms or disturbed experience but on the whole person, and health is not conceived as mere absence of disease but as full well-being instead [12]. This shift of perspective has been particularly evident in recovery research, which has offered more diversified concepts of recovery that go beyond mere remission of symptoms [13] and which has reshaped respective symptom- and deficit-oriented medical models in terms of ways in finding coherence, sense, and hope in life despite or even because of having symptoms [14]. Person-centered psychiatry thus also takes into consideration sources of psychological well-being, such as a person's resources, agency, and resilience [15, 16]. Importantly, this also means establishing participative and collaborative relations with service users within psychiatry $[17,18]$.

These approaches on well-being and recovery are echoed and integrated by Mezzich et al.'s [12] recent description of person-centered psychiatry, which entails 4 different but related perspectives: it is "of," "for," "with," and "by" the person. Person-centered psychiatry first of all needs to take into account the whole of both the patient's deficits and resources, that is, it is "of the person." At the same time it is "for the person," which means assisting and supporting the patient in her own recovery and well-being. Importantly, it must also be "with the person" - that is, taking patients seriously, empowering them, and actively including them in decision-making processes. Finally, "by the person" means that it should be practiced by clinicians both as professionals and as human beings. Whereas the first 3 aspects have been extensively accounted for by recovery-based and person-centered approaches, the last aspect, that is, the involvement of the person of the professional, has so far received less attention.

Probably as a reaction to the objectifying perspective of biological approaches that tend to disregard the person, person-centered psychiatry has indeed so far mainly focused on and emphasized the person and subjectivity of 
the patient. Yet, psychiatry does not happen individually but always in a relation with another person - that of the clinician. In the next section, we thus focus on the person of the therapist, more specifically on her stance and on its implications for the person-centered approach.

\section{Personhood of the Therapist and Stance}

In person-centered psychiatry, the subjectivity of professionals has been the focus of attention, mainly for the role of empathy in the process of understanding patients [19]. Empathy and compassion include and are based on the therapist's ability to sympathetically listen to the other and also on his or her own representations of the clinical situation. These aspects of the professional's subjectivity have been considered as a way to access the subjectivity of the patient and have thus been especially recognized as a diagnostic tool [12, 20-22]. Yet, far less attention has been paid to the fact that a professional's subjectivity can also have immediate therapeutic consequences - for example, by shaping the therapeutic relationship in the first place, which has a well-known impact on therapeutic outcome.

A neglect of the therapist's person can also be found in psychotherapy research $[23,24]$. Despite an initial interest for the therapist variables [25], the need to standardize and manualize therapeutic interventions often led to a de-personalization of therapy: the therapist was considered as a neutral means for administering manualized treatment in the same way a medical doctor would administer a pill [26] (see also "the drug metaphor" [27]). Only gradually has such a medical model been replaced by a more contextual approach and also by a renewed interest for the effects of therapists on patient outcomes [28]. More specifically, in the last decades, there has been a growing attention for the therapist's personal characteristics mainly in terms of psychotherapeutic and psychiatric competences and on how these can be trained and developed [29, 30]. Recent evidence has shown that the variability in the therapist's personal and professional competences impacts patient outcome (e.g., [31, 32]) even beyond the effect of the variability of methods [33].

This evidence supports the idea that the person of the patient cannot be considered independently from the person of professionals. As soon as patients enter a therapeutic or, more generally, a help-seeking relationship, the personhood of the people involved becomes intertwined, as they affect each other. The personhood of therapists can thus have immediate therapeutic consequences,

Person-Centered Psychiatry as Dialogical Psychiatry which ought to be investigated in more detail. Still, is it just the professional competence that matters and affects patients? Some studies have shown that also other personal aspects, such as the therapist's attachment style [34], personality traits [31], interpersonal history, and self-concept [32], have a significant impact on patient outcome. Interestingly, the effect of the therapist's characteristics may also depend on interpersonal factors such as how therapists and patients are matched [35]. The person of the therapist and her influence on the therapeutic relationship thus certainly include but also go beyond her specific clinical competencies [36]. One might generally say that, as a result from her participating as a person in the clinical situation, she assumes a particular stance, which includes, for example, competencies, beliefs, and emotions. In order to better grasp the effect of the therapist's personhood in its different facets and complexity, we therefore suggest focusing on the concept of therapeutic stance.

Although widely used in the psychiatric and psychotherapeutic literature, the notion of therapeutic stance has remained largely unspecified and has received remarkably little research attention [37]. We draw here on a philosophical notion of stance by Kurbacher [38], which we believe allows for an integration of manifold aspects of human experience and also mirrors the complexity of the notion of personhood. With the German term Haltung (= stance, posture, and attitude) Kurbacher [38] describes a person's way of relating to the world and to others both actively and passively, consciously and unconsciously. This includes rational and ethical attitudes and more basic emotional, perceptual, and cognitive dispositions. The bodily dimension is crucial here, as all the aforementioned aspects are always expressed through body postures. A person's posture (Körperhaltung) is never only a spatial configuration of body parts but has always a more encompassing expressive, symbolic, and social meaning that affects and is affected by others [38]. Consequently, a stance is a holistic phenomenon integrating categories that in the Western culture have long since been separated from one another, such as spirit and body, the conscious and the unconscious, theory and practice, or individuality and sociality.

Moreover, for Kurbacher [38], a stance is not only a holistic but also an interpersonal expression of somebody's personhood: the stance constantly mediates our personhood to the interpersonal space. Through our stance, we are practically and bodily engaged with the other person - and as therapists with our patients in the therapeutic space. We are responsive to others and call for 
others being responsive to us. The stance is the way through which we express ourselves to others and are affected by their expression. Although it is expressed by the individual person, the stance is thus a fundamentally relational concept, which is most relevant to our question of the therapist's personhood in the context of psychotherapy.

\section{Inter-Person-Centered and Dialogical Psychiatry}

\section{The Interpersonal Dimension: Describing the \\ Therapeutic Stance}

We have argued that personhood is always also interpersonal, in that it immediately, pre-reflectively and bodily expresses itself through a stance and thereby automatically shapes the interpersonal space. A description of the therapeutic stance is thus essentially linked to its interpersonal impact on patients and can only be described as it emerges and plays out in the in-between of persons. In this last section, we take a step forward, claiming that a truly person-centered psychiatry must necessarily be inter-person-centered because the personhood of professional and patient are directly interrelated and mutually influential.

In order to analyze and outline the intersubjective unfolding of the therapist's stance (and thus of her personhood) in more detail, we now return to the example of schizophrenia in the context of psychiatric and psychotherapeutic treatment. In particular, we focus on specific aspects of the professionals' stance and on their possible (hindering or helpful) impact on the therapeutic process and on the person of the patient.

Looking at the therapist's stance through the eyes of the patient, we first present an autobiographical quote by Deegan [39], who talks about her experience of being diagnosed with schizophrenia and of a particular stance by professionals:Granted, people gave me medication, psychotherapy, occupational therapy, and recreational therapy with me. But in a very fundamental way, I experienced myself as being all alone, adrift on a nameless sea without compass or bearing. And that deep sense of loneliness came from the fact that although many people were talking to me about my symptoms, no one was talking to me about how I was doing. No one came to me and said "Hey, I know you're going through hell right now. (...) I am around if you want to talk." (pp. 359-360)

In this quote, Deegan describes her feeling of not being recognized and seen as a person. The stance of professionals that yields such a feeling is an objectifying one, in which they regard her as a mere "symptom-carrier" instead of addressing her as a fellow person. Not only does she not feel recognized and seen as a person, but she also experiences the personhood of the therapist as missing. Indeed, she wishes for the professionals to potentially offer their presence - "I am around, if you want to talk" which implies the actually experienced absence of them as available interactional partners. The felt lack of personhood on both sides inevitably leads to a lack of inter-personality and thus to the feeling of being alone: despite the proliferation of therapeutic offers, there seem to be no tangible persons or interpersonal space attached to them.

This example first of all underlines the strong - in this case negative - and immediate repercussions of the professional's stance in shaping the interpersonal therapeutic space and in affecting the other person in her recovery process. Deegan here describes what - in the therapist's stance - made her feel less of a person, disoriented and alone. This stance might be viewed as typical of a medical model, which mainly focuses on the single symptoms instead of addressing the person in her entirety. In Deegan's words, the possible negative interpersonal effect of such a stance becomes clear. But how should then a therapeutic stance for persons with schizophrenia look like, that is, one that supports and strengthens the personhood of patients instead of reducing it?

To explore this question, we turn to alternative approaches in psychiatry, which in contrast to the medical model put more emphasis on the psychotherapeutic process. First of all, we have seen how the abovementioned person-centered approach by Mezzich et al. [12] emphasizes the importance of a more respectful and empowering stance toward patients, in that they are encountered, fully recognized, and actively included as persons. Besides, one can also find descriptions of a therapeutic stance in the different psychotherapeutic traditions: both in psychodynamic [40] and in cognitive-behavioral [41] as well as in systemic [42] approaches, several authors have stressed the importance of a participative, empathic, and open stance toward patients, notably in the case of psychosis. In psychodynamic psychotherapy for psychosis, von Haebler [43] has especially emphasized the importance of reciprocity and resonance in the therapist's stance as a precondition for the creation of a safe and inclusive therapeutic space. Such characterizations of the therapeutic stance are in common with other social-psychiatric approaches for the treatment of schizophrenia, such as Soteria [9], Psychosis Seminars [10] and the Open Dialogue [44]. Especially in the Open Dialogue approach, what von Haebler and colleagues [40] describe as reci- 
procity is conceived in terms of a dialogical stance [44] (for its philosophical underpinnings see also [45]). A dialogical stance implies taking seriously, including and making space for (at least) 2 active participating persons. In contrast to Deegan's account, in which the professional's stance seems to neglect both persons (therapist and patient), a dialogical therapeutic stance should thus foster and support the affirmation of both. Because the dialogical stance might in principle allow the recognition and inclusion of all persons, we believe it to be of particular importance for person-centered psychiatry - which, we have argued, must actually be inter-person-centered. In what follows, we therefore take a closer look at the specific components of the dialogical stance and at why and how it might have a supporting function for personhood, which we deem to be especially important in the case of schizophrenia.

\section{Openness and Authenticity: The Dialogical Stance}

Several authors have dealt with dialogical relations and structures in the context of psychotherapy [46-48]. As a thorough discussion of this literature is beyond the scope of this article, we here limit our focus to the dialogical structure of the therapist's stance and base our reflections mainly on descriptions of dialogue from the Open Dialogue approach. Galbusera and Kyselo $[6,49]$ have recently explored the dialogical stance on the basis of descriptions of Open Dialogue theory and practice. They suggested that a dialogical therapeutic stance is characterized by a 2 -fold structure, which includes 2 necessary and sufficient components: openness and authenticity. We here follow this suggestion and shed light on these 2 aspects through first person-accounts.

Schulz (in von Peter and Schulz [50]) a psychiatry-user and peer support worker (or recovery companion), describes what a good therapeutic stance might look like:For me, a good therapist doesn't have to speak about his ruptures, or tell me about his problems. It's important for me that I can feel that this person has experienced a lot. He knows ruptures, he knows crises, he doesn't stand apart from all that. And it's precisely from this experience that he understands or asks interested questions. He doesn't despise me because I'm sitting there as a person in need and our relationship is unbalanced. [...] As a recovery companion, I'm also the one who assumes this role. I never tell anyone my story. I never tell anyone anything without a reason. But I sit there as someone who is absolutely perceptible as a person with my own feelings. (p. 1294)

von Peter and Schulz [50]emphasiz a first important aspect of a stance experienced as therapeutic: authentici- ty. An authentic stance transpires from this quote in that the therapist (here the peer support worker) shows herself - even in her vulnerability - and becomes tangible for the patient. Authenticity is thus mainly about making space for one's own person as therapist, about being involved and using one's own subjectivity as a sensorium in the therapeutic process. Yet, as von Peter and Schulz [50] emphasize, this does not mean that the therapist invades or takes on all the therapeutic space with her own person by, for example, "speaking about his ruptures or problems." Authenticity means to make one's own person perceivable for the other in the way we respond and contribute to the interaction. It thus implies a rather active and expressive stance - an enactment of one's own personhood.

Even if not with the same intensity, in von Peter and Schulz [50] account also emerges another important therapeutic aspect of the stance: openness. This entails for instance being nonjudgmental, acknowledging the other, taking her seriously, showing interest in her idiosyncratic experience, and being ready to adapt to her. The effect that an open therapeutic stance can have on persons with psychosis is exemplified in the following quote by Amy Johnson [51], where she explains Larry Davidson what she experienced as helpful in her recovery process:I need not be ashamed when I am not well. I can go as is. I can sit right next to you at the table even when I'm sick; you do not make me sit outside or sit under your chair when I'm sick. And this helps me. Your acceptance of me as a person always, regardless of my wellness or unwellness status, is so healing, is so life giving, that I am still alive, Larry, in spite of the bed bugs, in spite of incest flashbacks that as of the past 24 hours have me obsessed with blood and cutting open my flesh, despite the voices that I hear with my ears, despite the stress of that I owe the Social Security Administration, the slum landlord, and the rest. (p. 78)

Openness here describes a stance in which the therapist makes space for and includes the person of the patient: irrespective of how she is, or how incomprehensible her experience might be, she has the right to take up a space as a person and to be addressed as such in the interpersonal encounter. Whereas being authentic implies an enactment or act (of showing oneself), an open stance is more at the receiving end: it implies both offering space for the other's expression and listening, adapting, and bracketing off one's own assumptions in order to "receive" the other's expression and enactment (see [6, 49] for a more detailed description of openness and authenticity). 
Thoma [52] has recently emphasized the centrality of these 2 aspects for the therapeutic stance by exploring them from a phenomenological perspective and more specifically by drawing on the work of the French philosopher Henri Maldiney [53]. One might argue that Maldiney's concepts of receptivity (transpassibilité) and responsivity (transpossibilité) indeed mirror what is at the core of an open and authentic stance. On the one hand, openness might be better understood through the idea of receptivity, which in psychotherapy refers to the professional's readiness to be surprised or even unsettled by her patients and their experiences, to let them speak for themselves, and to let them appear as who they are without imposing any psychiatric classification on them. On the other hand, the essence of authenticity might be captured by what Maldiney defines as responsivity, which in therapy for him implies a stance where therapists respond spontaneously and creatively to their patients' needs without hiding behind premanufactured textbook-responses or behind their professional role.

Yet at the same time, authenticity does not mean to deny one's professional role and expertise but to rely on it and express it as a part of one's own subjectivity $[6,52]$. Take for instance a clinical encounter with an acute psychotic patient, who is so deeply entangled in his delusion to the point of putting himself or other persons in danger: in this case being authentic means for the therapist to also act upon her own professional responsibility, as a nondeniable part of her person. The therapist might - through an open stance - take the patient seriously and for instance acknowledge his strong emotions and fears, listen and adapt to his needs; at the same time, she might also - through an authentic stance - act upon her professional knowledge and expertise on how to ensure the patient's safety.

Importantly, an authentic enactment of one's own professional responsibility and knowledge means to conceive these as an expression of the therapist's person (her stance) - to be communicated and negotiated in the interaction - and not as an absolute truth or authority. In the given case, this could mean that the therapist on the one hand authentically expresses her opinion that restrictive measures are necessary to ensure the patient's safety but on the other hand leaves the actual enforcement of such measures open for negotiation with the patient as long as possible (e.g., if measures are taken, which kind of measures). In this way, professional expertise is not imposed upon the person of the patient but becomes tangible as a part of the therapist's person, as something one can relate to. Openness and authenticity thereby enable
- even and especially in critical situations - windows of dialogue, in that the therapist both engages with and is ready to adapt to the patient, and at the same time, in that she stands her ground and authentically conveys her own perspective. In the following section, we elaborate on the therapeutic effects that such an open and authentic, that is, dialogical stance might have on the person of patients, especially in the case of schizophrenia.

\section{Balancing Individuality and Sociality of Personhood}

Galbusera and Kyselo [6] have argued that the dialogical stance - because of its 2-fold structure of openness and authenticity - might have a strengthening and supporting effect on persons with schizophrenia. We here explain and expand this suggestion and elaborate on it by also highlighting its significance and implications for person-centered psychiatry.

This suggestion is based on a conceptualization of the human self that emphasizes its constitution through social processes of distinction (from others) and participation (in social relations). For our sense of self, we therefore at the same time need to engage in social relations and to experience ourselves as separate [54]. Such 2-fold characterization of being at the same time autonomous from and connected to others recalls a core characteristic aspect of personhood, as we have outlined above with reference to Plessner [4]: being a person means being selfreferring and autonomous and at the same time also being defined through social norms and social relations. By means of our "eccentric positionality," we constantly shift back and forth from a first-person perspective to a perspective "from without", that is, through the eyes of others.

Being a person thus means to exist as a result of a continuous tension between 2 opposite tendencies or needs: seeking social connection and emancipating from others, sharing other's perspectives and differentiating oneself from them. Because of this tension (or paradox), to be a person one needs to continuously balance and negotiate between the 2 needs. As we already mentioned above, this continuous balancing may result in an inherent feeling of vulnerability at the basis of human existence $[6,54]$, which might become more critical in the case of schizophrenia. Indeed, in schizophrenia the oscillation between the processes of participation (sociality) and distinction (individuality) can become more extreme, up to the point that they may be experienced as mutually exclusive, thus leading to the experience of extreme isolation or merging with others [5-7]. 


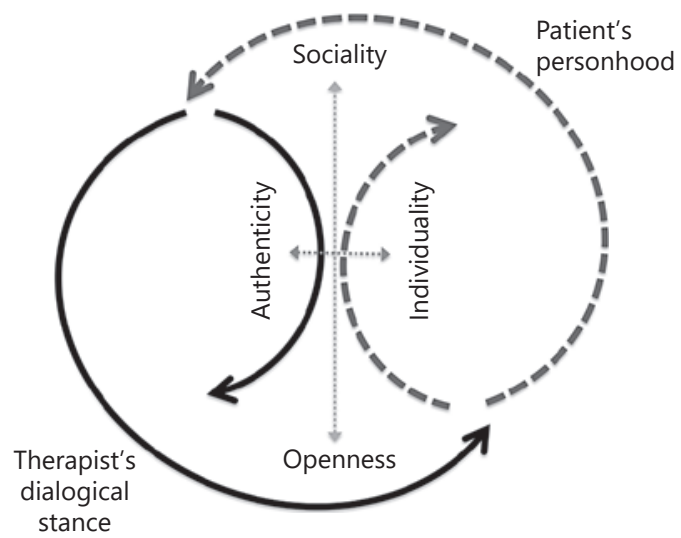

Fig. 1. The 2-fold structure of the dialogical stance (continuous line), which expresses the personhood of the therapist, calls for, fosters, and supports the 2-fold structure of personhood (dotted line) in the patient. The figure is taken and adapted from Galbusera and Kyselo [6].

In such cases, the dialogical stance is what might contribute to a rebalancing of the dimensions of individuality and sociality in the other person. The basic idea is that the 2-fold structure of the dialogical stance - based on openness and authenticity - mirrors and thereby fosters the 2-fold structure of personhood - that is, participation (sociality) and distinction (individuality). Let us briefly explain how this rebalancing takes place (Fig. 1).

A dialogical stance emphasizes and actualizes a copresence of individual and social in that it allows for the inclusion of both self and other in the interpersonal encounter. On the one hand, through openness, the therapist invites the patient as a person to actively enter into the interaction, and on the other hand, through authenticity, she also does so herself. Thereby - that is, through her open and authentic stance - she creates and shapes a dialogical interpersonal space, which allows the recognition and inclusion of both persons as separate individuals and at the same time enables a space for participation and sociality [6].

Importantly, through a dialogical stance, individuality and sociality are not only balanced in the interpersonal encounter but also at the intrapersonal level. By adopting a dialogical stance, professionals treat and support the patients as persons both in their social needs and in their need for emancipation and individuality. By being open, the therapist calls for social connection and sharing and for the other person to actively enter into interaction. By responding authentically, she asserts her own individual- ity (thus also creating a boundary), while inviting the other to do the same. By constantly counterbalancing each other, openness and authenticity thus also enable and support the copresence of sociality and individuality within the person. Through a dialogical stance the therapist recognizes, enacts, and allows the copresence of these 2 needs or tendencies within the patient. Consequently, this stance per se has an immediate therapeutic effect, in that it functions as a supporting structure for the actualization and strengthening of the patient's person in her wholeness - as a social and individual subject. This is particularly relevant for schizophrenia, where, as mentioned above, the person might particularly struggle to integrate her need for social connection and for individuation [6].

We have emphasized that and how a dialogical stance - because of its 2-fold structure of openness and authenticity - might support and strengthen personhood in the patient, in that it mirrors and fosters the 2 -fold structure of personhood - based on individuality and sociality. Following these considerations, we thus believe that a truly inter-person-centered psychiatry cannot but be a dialogical one.

\section{Conclusion}

The goal of this article was to offer reflections pertaining to the importance not only of the personal but also of the interpersonal dimension for person-centered psychiatry. To do this, we first emphasized the necessity of broadening the focus to the person of the therapist and her stance. Our considerations on the therapeutic stance helped us then to more specifically ground and justify our claim that person-centered psychiatry ought to be based on a dialogical stance of professionals. Indeed, adopting a dialogical stance means not only to recognize but also to actively support and strengthen the personhood of patients by fully participating as persons. We have therefore finally suggested that a person-centered approach should be reframed into an inter-person-centered and dialogical one.

A further crucial implication of our argument is that a therapeutic dialogical stance based on openness and authenticity is not to be understood as a moral imperative (as sometimes proposed in social psychiatry [55]) but, importantly, as a clinical necessity, whose therapeutic effect can be scientifically grounded on the very structure of personhood. Still this does not mean that such a stance is only relevant within the clinical domain. We indeed believe that a dialogical stance should not be restricted to 
mental health professionals and psychotherapy, but it also is of crucial relevance at a broader societal level. Once again, this becomes especially clear when looking at the example of schizophrenia: the loss of dialogical connection to the social world that persons with schizophrenia undergo is still and all too often mirrored by society's loss of dialogue with them, as for instance research on stigma has shown (e.g., [56]). We thus believe that a dialogical stance could help prevent social stigma by acting on public opinion toward persons with mental illness and by recognizing them as full-fledged members of society. Again, this is not in the sense of a moral call but as the enactment of a therapeutic principle at the societal level. Finally, this should lead to the creation of "niches of hospitality," where a dialogue between community members on living with mental crises can be established [57]. With these remarks, we would like to finally emphasize that any reflection on person-centeredness in psychiatry must always take into consideration the interpersonal and societal background in which psychiatry (and medicine as a whole) is embedded - and how it might affect it.

\section{Acknowledgments}

We would like to thank the 2 anonymous reviewers for their helpful comments and remarks.

\section{Conflict of Interest Statement}

The authors have no conflicts of interest to declare. All co-authors have seen and agree with the contents of the manuscript, and there is no financial interest to report.

\section{Funding Sources}

The study was funded by Internal Funding of the Brandenburg Medical School, Germany.

\section{Author Contributions}

L.G. and S.T. wrote the manuscript, which was revised and approved by T.F. and R.M.H.-H.

\section{References}

1 Sass LA. Madness and modernism: insanity in the light of modern art, literature, and thought. New York: BasicBooks; 1992.

2 Bührig M. Zur Grundhaltung des Personenzentrierten Ansatzes. In: Heinze M, Schlimme JE, Kupke C, editors. Personalisierte Psychiatrie: zur Kritik eines Konzepts. Berlin: Parodos; 2013. p. 77-84.

3 Fuchs T. Personalisierte Psychiatrie? Eine Kritik und Gegendarstellung. In: Heinze M, Schlimme JE, Kupke C, editors. Personalisierte Psychiatrie: zur Kritik eines Konzepts. Berlin: Parodos; 2013. p. 85-97.

4 Plessner H. Levels of organic life and the human: an introduction to philosophical anthropology. New York: Fordham University Press; 2019. (German original published 1928).

5 Kyselo M. The enactive approach and disorders of the self - the case of schizophrenia. Phenom Cogn Sci. 2016 Dec;15(4):591-616.

6 Galbusera L, Kyselo M. The importance of dialogue for schizophrenia treatment: conceptual bridges between the open dialogue approach and enactive cognitive science. Humania Mente J Philos Stud. 2019;12(36):26191.

7 Benedetti G. Todeslandschaften der Seele: Psychopathologie, Psychodynamik und Psychotherapie der Schizophrenie. Göttingen: Vandenhoeck \& Ruprecht; 1983.

8 Tatossian A. La phénoménologie des psychoses. 3rd ed. Paris: Le Cercle Hérméneutique; 2002.
9 Mosher LR, Hendrix V, Fort DC. Soteria: through madness to deliverance. Bloomington: Xlibris; 2004.

10 Bock T, Priebe S. Psychosis seminars: an unconventional approach. Psychiatr Serv. 2005; 56(11):1441-3.

11 Rogers CR. Client-centered therapy. Boston, MA: Houghton Mifflin; 1965.

12 Mezzich JE, Botbol M, Christodoulou GN, Cloninger CR, Salloum IM, editors. Person centered psychiatry. Cham: Springer International Publishing; 2016.

13 Barber ME. Recovery as the new medical model for psychiatry. Psychiatr Serv. 2012 Mar;63(3):277-9.

14 Davidson L. Living outside mental illness: qualitative studies of recovery in schizophrenia. New York: NYU Press; 2003.

15 Deegan PE. The importance of personal medicine: a Qualitative Study of resilience in people with psychiatric disabilities. Scand J Public Health Suppl. 2005 Oct;66(66_Suppl 1):29_ 35.

16 Cloninger CR, Salloum IM, Mezzich JE. The dynamic origins of positive health and wellbeing. Int J Pers Cent Med. 2012;2(2):179-87.

17 Deegan PE, Drake RE. Shared decision making and medication management in the recovery process. Psychiatr Serv. 2006 Nov; 57(11):1636-9.

18 Mezzich JE. The dialogal basis of our profession: psychiatry with the person. World Psychiatry. 2007 Oct;6(3):129-30.
19 Botbol M, Lecic-Tosevski D. Person-centred medicine and subjectivity. In: CorneliusWhite J, Motschnig-Pitrik R, Lux M, editors. Interdisciplinary applications of the personcentered approach. New York: Springer; 2013. p. 73-9.

20 Pallagrosi M, Fonzi L, Picardi A, Biondi M. Assessing clinician's subjective experience during interaction with patients. Psychopathology. 2014;47(2):111-8.

21 Rümke HC. Eine Blühende Psychiatrie in Gefahr: Ausgewählte Vorträge und Aufsätze. Heidelberg, NY: Springer; 1967.

22 Sholokhova S. Tracing the phenomenological psychopathological analysis to its source in the subjective experience of a psychiatrist. Horizon Stud Phenomenol. 2018;7(2):43051.

23 Garfield SL. The therapist as a neglected variable in psychotherapy research. Clin Psychol Sci Pract. 1997;4(1):40-3.

24 Beutler L. The psychotherapist as a neglected variable in psychotherapy: an illustration by reference to the role of therapist experience and training. Clin Psychol Sci Pract. 2006;4: 44-52.

25 Beutler LE, Machado PPP, Neufeldt SA. Therapist variables. In: Bergin AE, Garfield SL, editors. Handbook of psychotherapy and behavior change. 4th ed. Oxford, England: John Wiley \& Sons; 1994. p. 229-69.

26 Bergin AE, Garfield SL, editors. Handbook of psychotherapy and behavior change. New York: Wiley; 1994. 
27 Stiles WB, Shapiro DA. Abuse of the drug metaphor in psychotherapy process-outcome research. Clin Psychol Rev. 1989 Jan;9(4): 521-43.

28 Lutz W, Barkham M. Therapist Effects. In: Cutin RL, Lilienfeld SO, editors. The cncyclopedia of clinical psychology. Oxford, England: John Wiley \& Sons; 2015. p. 1-6.

29 Weck F. Psychotherapeutische Kompetenzen: Theorien, Erfassung, Förderung. 3rd ed. Berlin: Springer; 2014.

30 Radden J, Sadler J. The virtuous psychiatrist: character ethics in psychiatric practice. Oxford: Oxford University Press; 2010.

31 Heinonen E, Lindfors O, Laaksonen MA, Knekt $\mathrm{P}$. Therapists' professional and personal characteristics as predictors of outcome in short- and long-term psychotherapy. J Affect Disord. 2012 May;138(3):301-12.

32 Lingiardi V, Muzi L, Tanzilli A, Carone N. Do therapists' subjective variables impact on psychodynamic psychotherapy outcomes? A systematic literature review. Clin Psychol Psychother. 2018 Jan;25(1):85-101.

33 Lindgren O, Folkesson P, Almqvist K. On the importance of the therapist in psychotherapy: a summary of current research. Int Forum Psychoanal. 2010 Dec;19(4):224-9.

34 Black S, Hardy G, Turpin G, Parry G. Selfreported attachment styles and therapeutic orientation of therapists and their relationship with reported general alliance quality and problems in therapy. Psychol Psychother. 2005;78(3):363-77.

35 Werbart A, Hägertz M, Borg Ölander N. Correction to: matching patient and therapist anaclitic-introjective personality configurations matters for psychotherapy outcomes. J Contemp Psychother. 2018 Dec;48(4):253-1.
36 Heinonen E, Knekt P, Jääskeläinen T, Lindfors $\mathrm{O}$. Therapists' professional and personal characteristics as predictors of outcome in long-term psychodynamic psychotherapy and psychoanalysis. Eur Psychiatry. 2014 Jun; 29(5):265-74.

37 Jørgensen CR. The basis of the psychotherapeutic stance. In: Jørgensen CR, editor. The psychotherapeutic stance. Cham: Springer International Publishing; 2019. p. 117-37.

38 Kurbacher FA. Zwischen Personen. Eine Philosophie der Haltung. Würzburg: Königshausen und Neumann; 2017.

39 Deegan PE. Recovering our sense of value after being labeled mentally ill. J Psychosoc Nurs Ment Health Serv. 2015;31(4):7-11.

40 Lempa G, von Haebler D, Montag C. Psychodynamische Psychotherapie der Schizophrenien: Ein Manual. 2nd ed. Gießen: Psychosozial-Verlag; 2017.

41 Mehl S, Lincoln T. Therapie-Tools Psychosen. Weinheim: Beltz; 2014.

42 von Schlippe A, Schweitzer J. Lehrbuch der systemischen Therapie und Beratung I und II. 3rd ed. Göttingen: Vandenhoeck \& Ruprecht; 2016.

43 von Haebler D. Modifizierte, psychodynamische Behandlungstechnik und therapeutische Haltung in der Psychotherapie von Menschen mit Psychosen. Forum Psychoanal. 2015 Dec;31(4):395-413.

44 Arnkil TE, Seikkula J. Dialogical meetings in social networks. London: Karnak; 2006.

45 Buber M. Ich und du. Stuttgart: Reclam; 2008.

46 Lysaker PH, Lysaker JT, Lysaker JT. Schizophrenia and the collapse of the dialogical self: recovery, narrative and psychotherapy. Psychotherapy. 2001;38(3):252

47 Friedman M. Martin buber and dialogical psychotherapy. J Humanist Psychol. 2002 Oct;42(4):7-36.
48 Luft S, Schlimme JE. The phenomenology of intersubjectivity in Jaspers and Husserl: on the capacities and limits of empathy and communication in psychiatric praxis. Psychopathology. 2013;46:345-54.

49 Galbusera L, Kyselo M. The difference that makes the difference: a conceptual analysis of the open dialogue approach. Psychosis. 2018 Jan; 10(1):47-54.

50 von Peter S, Schulz G. "I-as-We" - powerful boundaries within the field of mental health coproduction. Int J Ment Health Nurs. 2018 Aug;27(4):1292-300.

51 Davidson L, Johnson A. Providing safety in the midst of psychosis: an interpersonal dimension of recovery. Psychosis. 2012 Oct; 6(1):77-9.

52 Thoma S. Into the open: on Henri Maldiney's philosophy of psychosis. Philos Psychiatry Psychol. 2019 Dec;26(4):281-93.

53 Maldiney H. Penser l'homme et la folie. 3rd ed. Editions Jérôme Millon; 2007.

54 Kyselo M. The body social: an enactive approach to the self. Front Psychol. 2014;5:986.

55 Thoma S, Galbusera L. Wie hältst du's mit der Haltung? Sozialpsychiatrische Informationen. 2021;2:50-4.

56 Schomerus G, Schwahn C, Holzinger A, Corrigan PW, Grabe HJ, Carta MG, et al. Evolution of public attitudes about mental illness: a systematic review and meta-analysis. Acta Psychiatr Scand. 2012 Jun;125(6):440-52.

57 Thoma S, Fuchs T. Inhabiting the shared world: phenomenological considerations on sensus communis, social space and schizophrenia. In: Hipólito I, Gonçalves J, Pereira JG, editors. Schizophrenia and common sense: explaining the relation between madness and social values. Cham: Springer International Publishing; 2018. p. 19-37. 